\title{
2
}

Blood Relations / Les Liens du sang 


\section{Une bouteille à la mer}

\section{Louise Dupré}

Between a woman, her mother and her grandmother lies the experience of death. Death of the body and death of language... How do mothers and daughters speak to each other? And does one write to break a filiation of silence?

Vous avancez sans savoir si vous traversez une ville, un ruisseau, un cimetière, vous vous contentez d'avancer, vous avancez dans le noir de vos yeux fermés, vous ne savez pas où vous mènera le chemin. Depuis que votre mère est morte, vous suivez une route élargie, mais sans lumière.

Votre mère est morte, vous le dites, mais elle est bien vivante encore. Vous le dites pour vous habituer, pour savoir le dire quand ce sera le moment. C'est peut-être un crime, peut-être une trahison, mais malgré tout vous le dites. Votre mère est morte. Vous voudriez que ce soit comme sa mère à elle. Sans agonie.

Un après-midi comme les autres, les intestins tout à coup se vident, on appelle, on a honte d'avoir souillé les draps blancs, et puis on meurt, dans la honte des matières sales. Votre mère est là. Vous êtes là, seules toutes les trois. Votre grand-mère, avec sa honte des intestins qui se vident, votre mère et vous.

Juste avant la mort, les intestins, a murmuré votre mère. Voilà ce que vous avez retenu de cette mort-là. Le corps qui, une dernière fois, fait son travail. Vous n'avez pas vu votre mort à vous. Les adolescentes ne peuvent pas voir ça. Votre mère, oui, vous en êtes sûre maintenant.

Ni héroïque, ni désespérée, la mort des femmes de votre sang. Elles ne vont pas à la guerre, elles ne se suicident pas. Une mort banale, qu'on ose à peine écrire. Comme la vie, sans fracas. Les années qui se suivent, les enfants, la nourriture tous les jours, les vêtements qu'on coud le soir à la lumière des lampes, plus tard les petits-enfants. Puis un jour le fil se casse, on ne l'a pas vu peu à peu s'effilocher. Aveuglément, c'est peut-être ainsi qu'il faut avancer. Vous ne faites pas autrement.

Mais vous exagérez. Elle voit, votre mère, elle a peur souvent. La peur de ne pas achever de s'éteindre, de s'éterniser dans une vie de 
morte-vivante. On ne peut pas savoir de quelle manière on finira. Elle l'avoue en chuchotant, tard le soir quand, dans l'immeuble où elle demeure, la vie est arrêtée. Elle l'avoue et vous cherchez des mots qui pourraient la rassurer, mais vous ne trouvez pas. Alors vous vous taisez. Vous écoutez.

Vous vous taisez, vous vous êtes toujours tue devant elle. Vous avez beau vous asseoir bien droite sur votre chaise, ouvrir la bouche, les mots s'agglutinent dans votre gorge, ils vous empêchent parfois de respirer et vous ne pouvez que répéter des phrases usées. Devant elle, vous êtes encore l'écolière qui lui rapportait de beaux bulletins pour la voir sourire, à la fin du mois. Vous étiez l'aînée, la petite fille parfaite, et vous reprenez votre rôle à chaque fois que vous lui rendez visite. Vos frères aussi. À défaut d'une vie facile, elle aura eu ça, de bons enfants.

Elle, elle aura été ce qu'on appelle une bonne mère. L'amour, les soins, la joie dans la maison malgré les problèmes, les devoirs puis les leçons après la classe. Et les livres de contes qu'elle vous lisait le soir, en vous mettant au lit, et les reproductions de tableaux qu'elle sortait doucement de leur étui les dimanches d'automne quand il pleuvait. Elle vous aura appris le nom de Renoir, de Cézanne, de Degas et de Monet bien avant le collège. Vous lui en êtes reconnaissante, vous le dites maintenant sans rancoeur, ce n'est pas parce que vous n'êtes jamais arrivée à parler avec elle que vous ne pouvez pas apprécier ce qu'elle a fait.

Parler avec elle, lui dire quelle femme vous êtes devenue au fil des ans, vous avez essayé. Mais vous vous êtes butée à un mur de silence, comme si elle n'avait pas entendu. Un jour, vous avez commencé à penser que, du fond de sa vie rangée, elle ne pouvait pas vous entendre, vous, avec vos grands dérangements. Elle avait peur de vous comme maintenant de la mort. Est-ce si difficile à comprendre?

Bien sûr, il a fallu finir par comprendre, mais encore aujourd'hui il vous vient un pincement au coeur. Parfois encore vous rêvez que votre mère vous parle comme à une femme. Vous vous asseyez devant elle, elle vous regarde en souriant, elle vous demande Comment vas-tu? avec une vraie voix. Et vous commencez à lui parler vous aussi avec une voix vraie. Mais vous revenez bientôt à la réalité.

Petit à petit on se rend à l'évidence, on ne peut changer personne, encore moins sa mère. Vous vous souvenez à quel moment précis vous avez renoncé. Un matin de neige, vous aviez décidé de lui parler de votre tante, vous avez employé le mot folle pour mettre des mots sur le passé. Mais vite votre mère a nié. Elle est revenue à ses vieilles 
conversations, la maison, les voisines, les emplettes de la semaine. Elle vous avait bien entendu pourtant, de cela vous êtes certaine, mais elle a refusé d'ouvrir la brèche que, pendant une fraction de seconde, vous avez aperçue dans ses yeux.

Vous dites brèche, mais ce mot est-il capable de nommer ce que jusque-là elle avait réussi à vous cacher? Depuis, vous savez cela, il y a une tache aveugle, un trou au milieu du paysage plat qu'a été sa vie, un gouffre qui la menace aussitôt qu'elle s'en approche. Alors, elle le contourne, elle l'entoure d'un mur de conformisme, elle fait toute chose comme elle doit être faite, elle dit, Il ne faut pas s'écouter. Elle aura passé sa vie à ne pas s'écouter.

Mais comment auriez-vous agi, vous, si un jour votre soeur était devenue folle sans qu'on sache la soigner? Les psychiatres, les électrochocs, les médicaments, et vos grands-parents qui n'arrivaient plus à s'occuper de votre tante, vous vous souvenez de ces conversations à voix basse lorsque vous étiez enfant. Vous vous souvenez que vous restiez bien sage en vous demandant si un jour, vous aussi, vous seriez internée. Et la peur sourde qui vous faisait venir le sang aux tempes.

Peur, peur, peur, décidément $c^{\prime}$ est ce que sans cesse vous ramène le passé. Votre mère aussi sans doute. Elle aura traversé sa vie comme une funambule, en mettant doucement les pieds l'un devant l'autre pour ne pas tomber. Vous auriez souhaité qu'elle puisse vous apprendre à courir ou à valser, mais c'est seule que vous avez esquissé vos premiers pas de danse. Plus jeune, vous lui en avez voulu, ne le niez pas, même quand il vous arrivait d'espérer. Vous vous voyiez marcher bras dessus bras dessous, toutes les deux, vous alliez au restaurant ou au concert, avec elle vous aviez ce plaisir qu'on a avec l'amie des belles confidences. Et puis, un jour, vous avez vu qu'elle était devenue vieille, et vous avez renoncé. Vous avez repris votre rôle de fille aimante.

Vous vous dites qu'entre vous, il n'y a pas eu de paroles, mais des tas de gestes. Les pots de confiture l'automne, les bas tricotés l'hiver, les blouses raccommodées près de la fenêtre. On peut aimer sans savoir parler. Votre mère vous aime, oui, vous aime comme une petite fille, mais non comme la femme qu'elle ne peut plus protéger. Cette femme-là lui échappe, elle ne veut en connaître ni la force ni les fragilités. Alors elle ramène à elle dans une bulle depuis longtemps crevée l'enfant brune aux yeux bruns, et elle vous raconte des anecdotes cent fois racontées. Pour masquer l'ennui, vous écoutez en guettant le moindre mot sous les mots, celui qui révélerait l'énigme de votre mère. 
Un jour, son ventre rendra ses dernières matières. Vous espérez être là, à côté, comme elle avec sa mère. Vous la nettoierez, vous ferez les gestes qu'elle faisait tous les jours avant que vous appreniez à parler. Vous direz à votre fille, Juste avant la mort, les intestins, en pensant à votre mort à vous. Comment réagirez-vous? La question vous vient parfois quand vous sortez de chez elle. Vous avez fait le deuil de sa parole, du moins il vous semble, mais au moment où votre mère fermera les yeux, vous éprouverez un immense regret. Le corps familier que vous recouvrirez d'un drap blanc sera resté jusqu'au bout celui $\mathrm{d}$ 'une étrangère. Vous vous reprocherez de ne pas avoir su faire surgir les confidences. Mais vous n'avez pas appris à parler, vous non plus.

Est-ce pour cette raison que vous écrivez, comme ces femmes dont vous ouvrez délicatement les livres, le soir, avant le sommeil? Muettes comme vous devant leur mère, c'est ainsi que vous les imaginez. Certaines viennent de pays que vous avez déjà traversés, d'autres de régions où vous ne vous rendrez jamais. Mais qu'importe, elles sont là, tout près, sous la lampe, elles laissent venir à vous leurs mots de souffrance, de larmes, de colère, de compassion, ou de bonheur parfois, elles vous font confiance, elles ne doutent pas de votre accueil.

Le beau mystère des livres: une bouteille jetée à la mer qu'une autre femme recueillera peut-être un jour. Vous aurez trouvé les mots qu'elle n'avait pas appris à prononcer, son coeur recommencera à battre dans sa poitrine, elle prendra sa plume, la remplira d'encre, noircira des pages et des pages, mais vous ne le saurez sans doute jamais puisque jamais vous ne la connaîtrez.

Vous écrivez avec le rêve d'une parole à partager. 